\title{
Função responsiva na fala de imigrantes alemães no Rio Grande do Sul
}

\author{
Vejane Gaelzer ${ }^{1}$
}

\begin{abstract}
Getúlio Vargas, in the 1930s and 1940s, in Brazil, after taking on the presidency, wants to institute a conception of Brazilian nation and also to implement a National's Plan that could be understood as a construction of a social imaginary of Brazilian Nation, of citizenship.

This article has the aim of rereading the historical happenings of the years 1930 and 1940 in Brazil. In order to investigate them we supported our studies around Bakhtin's (2004) conceptions, which proposed a challenge for perceiving the language, as a concrete social act, in an interactive perspective, which explores the conception of discourse in a social order. In this order the dialogue of voices beyond the linguistic norms, will be brought about. Conceptions produced by Mikhail Bakhtin, such as polyphony, dialogism, ideological signs and meaning will be explored in this study. According to the author, the word is plurivocal because it brings the voice of the other and answers to the other. In this sense our goal is to show the responsive function of the word in the discourse of the German immigrants at Rio Grande do Sul state. In order to do so, the discoursive corpus is constructed with of extracts of utterances of German immigrants that answer to the official discourses.
\end{abstract}

Keywords: Immigrant, language, responsive function, social voices.

Resumo: Getúlio Vargas, nas décadas de 1930 e 1940, no Brasil, após assumir a presidência visa a instituir uma concepção de nação e também implementar um Plano Nacional que pôde ser entendido como uma construção de um imaginário social de nação brasileira, de cidadania.

Este artigo tem o propósito de reler os acontecimentos históricos dos anos 1930 e 1940 no Brasil. A fim de investiga-los alicerçamos nossos estudos em torno das concepções de Bakhtin (2004) que lançaram um desafio de perceber a língua, enquanto ato concreto, social, numa perspectiva polifônica, que possibilita conceber os discursos na ordem do diálogo entre vozes sociais. A partir desta ordem o diálogo de vozes, para além das normas lingüísticas,

1 Professora do Instituto Federal de Educação, Ciência e Tecnologia - Campus Chapecó/Santa Catarina doutoranda da linha de Estudos da Linguagem, área de concentração Teorias do Texto e do Discurso, na Universidade Federal do Rio Grande do Sul. 
será posto em questão. Concepções produzidas por Mikhail Bakhtin tais como polifonia, dialogismo, signo ideológico serão exploradas neste estudo.

De acordo com o autor, a palavra é plurivocal porque traz a voz do outro e responde à voz do outro. Neste sentido, nossa meta é mostrar a função responsiva no discurso dos imigrantes alemães no Estado do Rio Grande do Sul. A fim de realizar este trabalho, o corpus discursivo é construído com extratos de proferimentos de imigrantes alemães que respondem ao discurso oficial.

Palavras-chave: Imigrante, língua, função responsiva, vozes sociais.

\section{Introdução}

Este artigo é resultado de reflexões posteriores elaboradas em torno do tema desenvolvido na Dissertação de Mestrado, intitulada "Da Palavra à Palavra: a constituição do Sujeito-autor". Nesta pesquisa, foram desenvolvidos alguns conceitos estudados por Mikhail Bakhtin (2004), tais como: dialogismo, polifonia, heteroglossia, gêneros discursivos. Bakhtin (id.), em seus estudos, traz conceitos inovadores para sua época que são, mais tarde, reconhecidos e aprofundados por outros autores.

Bakhtin (id.) lançou o desafio de perceber a língua, enquanto ato concreto, social, em uma perspectiva de interação, que possibilita considerar a situação social, histórica e ideológica do sujeito e esta situação interfere na construção e na compreensão dos enunciados. Nesta perspectiva, as palavras não constituem seus sentidos a partir da norma, mas a partir da realidade de quem enuncia e de quem as recebe. Isto significa que as palavras têm efeitos de sentidos de modo diferente, conforme a situação social, em que o sujeito está inserido. Portanto, segundo Bakhtin (id.), as palavras carregam posições axiológicas e trazem consigo outras vozes sociais, elas perdem sua neutralidade no momento em que se inscrevem em uma situação social concreta.

Neste sentido, este artigo procura contemplar e aprofundar a noção de função responsiva presente na obra 'Marxismo e Filosofia da Linguagem'(2004) de Mikhail Bakhtin , investigando as falas de imigrantes alemães, ao se referirem à época das décadas de 30 e 40, no cenário do Plano Político Nacionalista do Brasil.

\section{Sujeito e sentido}

Na concepção bakhtiniana de língua, há diferença entre sinal e signo. A língua enquanto sinal não tem valor expressivo, não significa nada. O sinal é apenas identificado, não produz reflexão e nem retrata nada, enquanto o signo, não é somente identificado, produz significações, faz refletir, porque "todo signo, inclusive o da individualidade, é social"'.

Para o autor, a sinalidade é dialeticamente deslocada, absorvida pela nova qualidade do signo. Todo signo é social por natureza, tanto o exterior quanto o interior. Por isso, o que torna a língua um signo não é o reconhecimento do sinal, mas a compreensão da palavra, ao produzir sentido em situações sociais de enunciações precisas, pois "a palavra está sempre carregada de um conteúdo ou de um sentido ideológico ou vivencial"3. Portanto, por este viés teórico, a língua é um sistema de signos sociais, como uma corrente ininterrupta, de forma que o locutor a utiliza para suas necessidades concretas e definidas.

\footnotetext{
2 BAKHTIN, Mikhail. Marxismo e Filosofia da Linguagem. São Paulo, Ed. Hucitec, 2004. Trad. Michel Lahud e Yara Frateschi.p.59

3 Idem. p.95
} 
Nesta concepção, não podemos falar de língua sem falar de sujeito, este inserido dentro de um processo sócio-histórico, assumindo uma posição que traz consigo juízos de valor. Dessa perspectiva, o sentido da palavra não pode ser entendido como único, estável e transparente, mas como efeito que é construído a partir de determinados lugares sociais e históricos, e o discurso mantém sempre relação com outros dizeres.

Para o autor, "as palavras são tecidas a partir de uma multidão de fios ideológicos e servem de trama a todas relações sociais em todos os domínios" ${ }^{\text {". }}$ O discurso, portanto, não é homogêneo, é atravessado por outros discursos e determinado sócio-historicamente, embora seja camuflada a heterogeneidade que o constitui. Nessa relação entre discurso e língua, a língua é neutra enquanto objeto, mas no momento em que se inscreve em uma ordem sócio-histórica, ela perde sua neutralidade. Esse outro olhar que Bakhtin (2004) lança sobre a língua nos abre espaço para percebê-la num viés social, onde de fato ela se transforma em linguagem. Os efeitos de sentido se dão na exterioridade e o sentido é efeito de determinadas condições sociais e históricas.

Conforme Lähteenmäkï (2005), a língua, percebida pelo viés social, revela-se como Raznorechie, isto é, a expressão viva da fala dos sujeitos, a própria heteroglossia. Neste sentido, para Bakhtin (2004), na perspectiva polifônica e dialógica, a língua e a fala não se desvinculam, pois a unidade real da língua é realizada na fala, sendo esta, portanto, em sua totalidade, concreta, viva, social. Para tanto, o valor não está preso à língua, a exterioridade é constitutiva da mesma e todo dizer significa a partir de algum lugar social e histórico. A consequência disto é que o sentido não pode ser controlado como efeito de uma voz uníssona, ele se produz num espaço de fronteiras e de deslizamentos. No domínio dos signos, cada esfera ideológica tem seu modo de apreender a ordem do real. Para Bakhtin (2004), o signo linguístico ao se inscrever numa ordem histórica e simbólica, torna-se um signo ideológico que passa a refletir e refratar outra realidade.

Em 'Estética da Criação Verbal (2003) Bakhtin defende que "a palavra deve deixar de ser sentida como palavra" ${ }^{5}$ neutra, pois esta está imbuída de posições axiológicas. As palavras ao serem empregadas trazem consigo um juízo de valor, um "tom valorativo" ${ }^{6}$ presente nos processos e práticas discursivas. A cada nova situação social, a palavra tornase outra e a cada nova (re)assimilação adquire novo significado. Em qualquer momento, o sujeito faz uso da palavra numa perspectiva dialógica, pois na sua voz ecoam outras vozes sociais. A palavra "saindo" do sistema da língua, ou seja, usada numa situação de comunicação discursiva, torna-se parte integrante do enunciado, numa relação dialógica, significando de forma múltipla. Por esse viés, podemos dizer que o locus social, no qual o sujeito está inserido, determina a posição assumida. O sujeito inacabado está em contato com outras vozes que o integram numa relação dialógica sempre a partir da palavra do outro.

\subsection{Interação Dialógica de Vozes Sociais na Constituição da Weltanschauung7 de Imigrantes}

Conforme Bakhtin (2004), a expressão comporta duas faces: o conteúdo (interior) e sua objetivação exterior para outrem, portanto, o ato expressivo move-se entre as duas, pois procede de alguém, assim como se dirige a alguém. Ao contrário do que muitos afirmam, Bakhtin (id.) nos diz que a expressão é efeito da interação do exterior e do

\footnotetext{
4 Idem. p. 41

5 Idem. p. 178

6 Ibidem. p. 132

7 Depreende-se de Weltanschauung a concepção de mundo, a visão que se tem do mundo.
} 


\section{Conexão Letras}

modo como a consciência responde ao exterior. Neste sentido, o discurso é determinado por diversos elementos e não se restringe apenas à expressão interior, porque as formas discursivas exteriores interferem na ordem discursiva interior, no socialmente dado. $\mathrm{O}$ discurso interior recebe o discurso do outro e o recompõe com aquilo que já tem. Para o autor, "pode-se dizer que não é tanto a expressão que se adapta ao nosso mundo interior, mas nosso mundo interior que se adapta às possibilidades de nossa expressão, aos caminhos e orientações possíveis".

Se nos debruçarmos sobre o estudo da Era Vargas, podemos perceber que os discursos não se dão no vazio, mas na situação sócio-histórica das décadas de 30 e 40, que define a condição identitária e social do imigrante e do brasileiro. É, neste período, que o governo aceita a vinda de imigrantes, e, ao mesmo tempo, cria uma série de mecanismos para controlar esses imigrantes. Dentre esses mecanismos, Getúlio Vargas institui a implementação do Plano de Nacional, que traduz a construção de um imaginário social de nação brasileira, de cidadania, e, assim, oficializa um Projeto Político de Nacionalização, objetivando a consolidação de uma "consciência nacional". A política de nacionalização implica em legitimar algumas práticas e expurgar outras que ameaçavam esse projeto. Para tanto, o governo cria um discurso de um país miscigenado, unido por uma única língua e uma consciência nacional. A partir dessa política, desenvolvem-se algumas práticas e discursos que determinam comportamentos e lugares sociais. Neste cenário de imaginário de brasilidade, exclui-se o sujeito imigrante e constrói-se um olhar sobre ele, determinando-o socialmente e buscando apagar a sua identidade, sua memória e a sua história. Neste sentido, os discursos dos imigrantes funcionam como respostas a essas práticas e discursos e nos esboçam a situação por eles vivida.

O recorte tomado de um imigrante ilustra a situação de repressão policial, sofrida nas ruas da pequena cidade de Três de Maio, durante a hegemonia Vargas:

R1 (A): Houve fatos com crianças como era o caso de minha irmã, mais velha, que os policiais atacavam e queriam que ela falasse... queriam testar se ela soubesse falar o português e ela tinha dificuldade em falar em português e ela tinha um medo de encontrar um policial, porque os policiais cobravam, não se permitia, ah... falar alemão (EIHELBERGER, 2007).

Pelo recorte 1 (R1 doravante) podemos perceber, na prática, a construção do Projeto Político de Nacionalização na perspectiva dos imigrantes. Nas palavras deste imigrante, ecoa a memória sobre a situação de repressão vivida em relação à língua. A política de nacionalização do governo varguista proibia o uso de qualquer língua estrangeira e instituía a Língua Portuguesa, como sendo a única. Diante dessa medida de imposição, podemos perceber, no início do R1, que a Língua Portuguesa é uma forma de controle. Quando o imigrante afirma: "os policiais atacavam e queriam que sua irmã falasse... queriam testar se ela soubesse falar o português", encontramos um modo de verificar se as medidas de proibição de línguas estrangeiras, no caso, a língua Alemã, estavam sendo respeitadas, isto é, uma forma de controle identitário e cultural sobre os imigrantes. Ao mesmo tempo, no final da fala do recorte apresentado, transparece o medo por eles vivido em relação a esse controle, de modo que tentavam evitar o teste do conhecimento ócusstico, para que não descobrissem que não falavam o Português.

8 BAKHTIN, Mikhail. Marxismo e Filosofia da Linguagem. São Paulo, Ed. Hucitec, 2004. Trad. Michel Lahud e Yara Frateschi.p.118 
Pensar o discurso como um espaço de encontro de vozes, permite pensar o imigrante como um sujeito social que traz, no discurso, outras vozes, pensamentos, palavras, que fizeram - fazem - parte da sua realidade social, que permearam a sua história e que brotam ao falar.

Neste sentido, ao analisarmos as falas dos imigrantes e identificarmos vozes que habitam seus discursos, podemos trazer a polifonia de Bakhtin (2004), pois há a possibilidade de escutar os discursos e percebê-los a partir de uma situação sócio-histórica, cientes de que são resultado de (re)assimilações de vozes sociais e não apenas estruturas. Nestas falas, há a presença de vozes sociais que se ocultam sob a aparência de uma única voz, uma voz que se sobressai e se pronuncia sobre as outras, mascarando o diálogo. Portanto, ao observarmos as reflexões teóricas, a partir do R1, o discurso do imigrante está num constante diálogo com as práticas de repressão e de controle do Governo Vargas e com as palavras dos próprios imigrantes. $\mathrm{O}$ enfoque dado às palavras está relacionado com os saberes aceitos, conforme os discursos que se referem ao imigrante, e estes dependem da compreensão de mundo do sujeito e da situação social em que se encontra.

Em 'Problemas da Poética de Dostoievski (2005) Bakhtin observa que, longe de conviverem harmoniosa e consensualmente no interior do discurso, as múltiplas vozes estão, antes, em constante tensão que desembocam em contradições e descentramentos. Por causa desta convivência de múltiplas vozes, as palavras não são "nossas" apenas, elas nascem, vivem e morrem na fronteira do nosso mundo e do mundo alheio, participando desse mundo de múltiplas vozes, de deslocamento no plano da linguagem, pois “a palavra, a palavra viva, indissociável do convívio dialógico, por sua própria natureza quer ser ouvida e respondida"Minha palavra permanece no diálogo contínuo, no qual ela será ouvida, respondida e reapreciada" [...]. ${ }^{9} \mathrm{O}$ autor nos mostra que a constituição do discurso acontece no âmbito social numa interação dialógica de vozes, constituindo a Weltanschauung.

Nesse processo, aparece a manifestação de pluralidade de palavras, pois elas são combinadas de formas diferentes no enunciado. Neste sentido, Bakhtin (2004) propõe que o discurso não pode ser compreendido fora da situação social, pois o falante tem um destinatário real ou imaginário ao produzir sua fala, como se fosse uma resposta, numa interação ativa. Isso significa que as palavras da língua estão sempre inevitavelmente perpassadas pelas palavras do outro, elaborando uma resposta de seu próprio discurso. Dessa forma, há sempre a voz do outro presente na voz do falante, pois um discurso sempre se constitui numa relação de alteridade com o outro, "toda enunciação é uma resposta a alguma coisa construída como tal"10. Isso porque somos constituídos social e ideologicamente. Em qualquer discurso há um posicionamento do sujeito, uma vez que ao falar, este sujeito posiciona-se diante da situação e as palavras representam uma visão de mundo de quem enuncia. Portanto, conforme o autor, o discurso é um reflexo subjetivo do mundo objetivo, uma (re)leitura a partir da leitura alheia e esta é feita a partir do ócus social. Neste sentido, no discurso dos imigrantes, emerge um diálogo de vozes sociais, que institui posições sócio-axiológicas, porque ele é um reflexo subjetivo da Weltanschauung e efeito das palavras alheias.

9 BAKHTIN, Mikhail. Problemas da poética de Dostoiévski.. Rio de Janeiro, Forense Universitária, 2005. Trad. Paulo Bezerra, p.356

10BAKHTIN, Mikhail. Marxismo e Filosofia da Linguagem. São Paulo, Ed. Hucitec, 2004. Trad. Michel Lahud e Yara Frateschi. p.98 


\subsection{Ecos e Ressonâncias na Fala de Imigrantes}

As palavras, enquanto signos lingüísticos, são desprovidas oralmente de um autor, não assumem posições axiológicas, nada expressam. Bakhtin (2003) afirma que "as palavras em si não são de ninguém, em si mesmas nada valorizam, mas podem abastecer qualquer falante e os juízos de valor mais diversos e diametralmente opostos dos falantes" ${ }^{11}$. Por isso, sem uma situação social, sem um tom expressivo ${ }^{12}$, sem a alteridade, as palavras não passam de signos linguísticos abstratos e neutros. Entretanto, ao serem proferidas por alguém, na comunicação discursiva, assumem posições e recebem um sujeito e, no mesmo momento, são (re)assimiladas, reelaboradas e trazem ecos de vozes alheias. Portanto, o sujeito do discurso ao proferir suas palavras, habitado por palavras alheias, exprime sua visão de mundo e emite juízos de valor, desencadeados na interação com outro. Neste sentido, a interação acontece em uma situação sócio-histórica concreta. $\mathrm{O}$ enunciado carrega consigo a réplica possível, porque todo enunciado procede de alguém e dirige-se a outro, cuja compreensão responsiva ativa está no próprio enunciado. Toda compreensão supõe um diálogo, porque "compreender é opor à palavra do locutor uma contrapalavra"13. É como se, na compreensão, o interlocutor formulasse uma resposta ao enunciado do locutor, mesmo que essa resposta esteja apenas na compreensão interior, sem expressá-la oralmente. Os sentidos dos enunciados estão justamente nesse processo de interação entre quem diz e seus interlocutores, isto é, "no processo de compreensão ativa e responsiva" ${ }^{14}$. Os sujeitos ao falarem, respondem implicitamente ao discurso do outro num diálogo constante de vozes, sob aparência de uma voz.

A seguir, traremos um recorte da fala de uma imigrante que vive na cidade de Santa Rosa, localizada no interior do Estado do Rio Grande do Sul. Este recorte traz um relato sobre as práticas de violência simbólica sofridas durante o Governo Vargas:

R2(B) „Na ja, mein Vater mußte seine ganze Bücher nach Tuparendi nehmen - auf die Delegacia - Säcke voll. So gute Bücher, so schöner... Mein Vater war ja Pfarrer, er war ja garnicht politisch. Er hatte garnicht mit politik zu tun. Es waren Bücher für Pfarrer, aber es war auf Deutsch. Er mußte alles nach Tuparendi bringen. Sie haben es auf einander geworfen vor die Delegacia und alles verbrand ${ }^{15}$

Pela fala da imigrante do recorte 2 (R2) tomamos conhecimento sobre fatos ocorridos com bens de famílias de imigrantes alemães, como com os livros, e, ao mesmo tempo, esta traz uma resposta às práticas políticas de repressão da política de nacionalização do governo varguista, cujo objetivo era manter sob vigilância os comportamentos dos imigrantes e manter a ordem nacional. Assim, os imigrantes eram proibidos, além de falar alemão, de manter em suas residências qualquer material que estivesse nessa língua, mesmo que fossem livros de pregação religiosa. Pela afirmação da imigrante, "meu pai era pastor, ele nem era político", podemos perceber que o objetivo do governo estava

11 BAKHTIN, Mikhail. Estética da Criação Verbal.. São Paulo, Ed.Martins Fontes, 2003. Trad.: Paulo Bezerra. p. 190

$12 \mathrm{O}$ tom expressivo é uma característica referente somente ao enunciado não à palavra, pois o falante pode dar tons expressivos à mesma palavra, conforme contexto social concreto o exigir.

13 BAKHTIN, Mikhail. Marxismo e Filosofia da Linguagem. São Paulo, Ed. Hucitec, 2004. Trad. Michel Lahud e Yara Frateschi. p.132

14 Ibidem. p.132

15 "Meu pai foi obrigado a trazer todos os seus livros para Tuparendi - na delegacia - sacos cheios. Assim, bons livros, tão bonitos... Meu pai era pastor, ele nem era político. Ele não tinha nada a ver com a política. Eram livros para pastor, mas estavam em alemão. Ele precisou levá-los a Tuparendi. Eles os jogaram num monte na frente da delegacia e queimaram tudo"[Nossa Tradução]. 
claro para eles, pois sabiam que estavam sendo controlados e vigiados, e que tentavam afastá-los da política. A depoente reforça isto ao dizer que os livros "não tinham nenhuma relação com a política". Isto é uma resposta que procura refutar a ideia de que eles eram uma ameaça política à nação e mostra a ação violenta do governo, em nome da segurança nacional, para proteger o país de ideias contrárias.

Esta fala, "Livros assim tão bons, tão bonitos...Eles jogaram num monte na frente da delegacia e queimaram tudo", ilustra uma denúncia da repressão vivida por imigrantes na época e demonstra o que o governo procurou fazer com elementos identitários desses imigrantes. Desse modo, neste recorte, ecoa a Weltanschauung do Governo sobre os imigrantes: a de serem um perigo ao país e, portanto, precisavam ser anulados e ter a sua cultura e sua identidade substituídas.

O fato não era apenas ser imigrante, isto não era exatamente um problema, desde que o sujeito se assumisse como brasileiro e negasse qualquer laço com a sua história e a sua identidade. Sabemos que o governo varguista não estava apenas preocupado com a construção da identidade do povo brasileiro, a questão era política e a expressão "alles verbrandt", isto é, "queimaram tudo", ilustra as tentativas das práticas do governo em anulá-los culturalmente. Para os imigrantes, "alles", isto é, "tudo", que estava em Língua Alemã, representa um elo de ligação com a sua cultura e procuravam preservá-la. Portanto, ao queimar os livros está subententida a destruição simbólica desses imigrantes, determinando-lhes outros livros, outras leituras, outro sentimento de pertencimento.

A seguir, temos um recorte de fala de um imigrante da mesma cidade e este recorte também ilustra a repressão vivida, na época, por causa da Língua Alemã:

R3 (C): os livros, eram tudo perseguido, os panos de parede em alemão, foi tudo levado, foi arrancado da parede, né... porque eles eram perseguidos demais na época, ninguém podia ter nada em alemão...

O recorte 3 (R3), como o R2, revela a violência vivida pelos imigrantes. Nos dois recortes, fica clara a prática política xenofóbica por parte do governo varguista, tentando construir um sentimento da nacionalidade brasileira. A violência pode ser percebida no R3, ao imigrante se referir "foi tudo levado, foi arrancado da parede", como se fosse um modo simbólico de lhes arrancar a bagagem cultural, porque nada poderia lembrar-lhes a cultura alemã. Na fala ressoa a visão sobre este governo, que procura violentamente substituir a cultura. A afirmação, "Ninguém podia ter nada em alemão...", nos remete à anulação e à proibição dos elementos perigosos para a construção de uma união nacional em torno de uma única cultura brasileira. Criam-se mecanismos, nos quais os cidadãos se reconhecem como brasileiros e, para tanto, devem aplicar a lei àqueles que não a respeitam, denunciando e vigiando os que não se adaptam. Neste cenário, os imigrantes eram proibidos de falar alemão, ter livros, quadros ou panos de parede em alemão, administrar escolas, proferir cultos em alemão, não lhes era permitido atuar em atividades sociais, educacionais, muito menos, em atividades políticas. Temos, portanto, nessas práticas, um estado repressor e xenófobo, que pautado em respaldo jurídico, cria dispositivos para reprimir e anular o elemento ameaçador para o Plano Nacional.

\section{Considerações finais}

O trabalho aqui apresentado pretendeu refletir sobre a função responsiva das palavras nos discursos de imigrantes alemães.Para tanto, trouxemos alguns recortes de falas 


\section{Conexão Letras}

destes imigrantes. Investigar a função responsiva da palavra mobilizou algumas questões, como práticas políticas do Regime Vargas, as noções de signo ideológico, situação social e objeto simbólico. No centro dessas questões, temos a palavra, que se inscreve numa ordem social e simbólica para significar, tornando-se um signo ideológico que se produz no seio do campo social e histórico e que passa a refletir e refratar a realidade.

Neste sentido, as práticas discursivas estão ligadas às práticas sociais. A palavra plurivocal traz a voz do outro e responde ao outro. Dessa forma, ao nos debruçarmos sobre as falas dos imigrantes, percebemos que elas vêm carregadas de respostas às práticas políticas de violência, de controle e de repressão do governo varguista, cujo objetivo era colocar o imigrante na condição de inimigo do Estado.

Neste panorama, estes imigrantes se reconhecem e a partir daí procuram dizer que eles não eram uma ameaça ao país e à sua ordem e que não tinham relação com a política, possuíam livros relacionados à pregação religiosa ou panos de parede que compunham uma forma de enfeite e um modo de identificação. A Língua Alemã é um elemento simbólico que lhes remete a um sentimento de pertencimento e à preservação identitária. Portanto, as falas destes imigrantes precisam ser tomadas a partir da hegemonia política da Era Vargas e aí serem significadas; isto é, reconhecemos a relação de vozes que permeiam e constroem a historicidade destes imigrantes e buscamos a possibilidade de dar voz a estes que foram repreendidos e apagados sob a égide de uma voz mais forte, mascarando a violência e a repressão.

\section{Referências}

BAKHTIN, Mikhail. Estética da Criação Verbal.. São Paulo, Ed.Martins Fontes, 2003. Trad.: Paulo Bezerra

Marxismo e Filosofia da Linguagem. São Paulo, Ed. Hucitec, 2004. Trad. Michel Lahud e Yara Frateschi.

Problemas da poética de Dostoiévski.. Rio de Janeiro, Forense Universitária, 2005.

Trad. Paulo Bezerra

EIHELBERGER, Andreia; WEYDMANN, Fabiane. Guerreiros desta pátria: momentos amargos da nossa história. Ijuí, Ed. Unijuí, 2007.

GAELZER, Vejane. Da palavra à Palavra: a constituição do Sujeito-Autor. UNIJUÍ, IJUÍ, 2007. Dissertação de Mestrado inédita.

LÄHTEENMÄKÏ. Mika. Estratificação Social da Linguagem no Discurso sobre o Romance: o Contexto Social Soviético oculto. In: Mikhail Bakhtin: Contribuições para a Filosofia da Linguagem e Estudos Discursivos. ZANDWAIS, Ana (org.) Porto Alegre, Ed. Sagra Luzzatto, 2005.

REVISTA DO ENSINO DO ESTADO DO RIO GRANDE DO SUL. . Porto Alegre, Vol.1. n ${ }^{\circ}$, nov. De 1939, (ano I).

REVISTA NOSSO SÉCULO - 1930-1945. Capítulo VIII - “O Estado Novo”, Ed. Abril, p.193.

SERIÓT, Patrick. Bakhtin no Contexto: Diálogo de Vozes e Hibridação das Línguas (o problema dos Limites). In: Mikhail Bakhtin: Contribuições para a Filosofia da Linguagem e Estudos Discursivos. ZANDWAIS, Ana (org.), Porto Alegre, Sagra Luzzatto, 2005.

SILVA NETO, Casimiro Pedro da. Década de 1930 - Os Anos de Incertezas: A Origem da Primeira Lei de Segurança Nacional, 2006. In: www.cpdoc.fgv.br/nav_historia/htm/ anos37-45/ev_ecp_horabrasil.htm. 
TCHOUGOUNNIKOV, Serguei. Por uma Arqueologia dos Conceitos do Círculo de Bakhtin: Idologema, Signo Ideológico, Dialogismo. In: Mikhail Bakhtin: Contribuições para a Filosofia da Linguagem e Estudos Discursivos. Ana Zandwais (org.) Porto Alegre, Ed. Sagra Luzzatto, 2005.

ZANDWAIS, Ana (Org.). OS PLANOS NACIONAIS DE EDUCAÇÃO DOS GOVERNOS VARGAS E FHC: um Contraponto entre Saberes sobre Educação e Ensino de Língua Materna. In: Ensino e aprendizagem de línguas: língua portuguesa/ org. Ercília Cazarin, Gesualda dos Santos Rasia. Ijuí, Ed. Unijuí, 2007.

. Saberes sobre a identidade nacional: o processo de construção de um imaginário de cidadania durante o Governo Vargas. In: Análise do discurso no Brasil mapeando conceitos, confrontando limites. Org. Maria Cristina Ferreira, Freda Indursky. São Carlos, Ed. Claraluz, 2007. 